\title{
KINETICS MODELS FOR THE ELECTROCHEMICAL DECOLOURATION OF TWO REACTIVE AZO DYES
}

Víctor López-Grimau ${ }^{1,2}$, Montserrat Pepió $^{3}$ Carmen Gutiérrez-Bouzán ${ }^{1^{*}}$ and Valentina Con formato: Inglés (Reino Unido)

\section{Buscio $^{1}$}

${ }^{1}$ Institute of Textile Research (INTEXTER); Universitat Politècnica de Catalunya - Barcelona Tech; Terrassa, Spain.

${ }^{2}$ Department of Project and Construction Engineering; Universitat Politècnica de Catalunya Barcelona Tech; Terrassa, Spain.

${ }^{3}$ Department of Statistics and Operations Research; Universitat Politècnica de Catalunya Barcelona Tech; Terrassa, Spain.

Victor López-Grimau: victor.lopez-grimau@upc.edu

Montserrat Pepió: montserrat.pepio@upc.edu

Carmen Gutiérrez-Bouzán* (corresponding author): m.carmen.gutierrez@upc.edu Valentina Buscio: valentina.buscio-olivera@upc.edu

\section{Abstract:}

In this work, the indirect oxidation of two azo dyes (Colour Index Reactive Orange 4 and 13) was performed in an electrochemical batch cell in the presence of chloride as an electrolyte. The effect of different operational parameters on the electrochemical treatment was tested. Kinetics plots consisting of two linear portions were obtained in some experiments. The rate constants and the breaking point between the two linear portions were modelled to evaluate the influence of dye concentration, conductivity and $\mathrm{pH}$. Good correlation between the experimental and the modelled constants and breaking points was observed. Models showed that the dye concentration is the most significant factor in the electrochemical treatment of both dyes, although conductivity and $\mathrm{pH}$ were also significant either individually or in interaction with other factors.

Keywords: Electrochemical oxidation; Reactive dyes; Decolouration rate; Kinetics models; Factorial experimental design. 


\section{Introduction}

Dyes are an important class of organic macromolecules playing an integral part of our lives. They are used in numerous industries such as textile, leather, paper, rubber, plastics, cosmetics, pharmaceutical and food [1]. Textile dyes are registered and classified according to a colour index which depends on their molecular structure, source, colour and/or method of application. Taking into account the structure of their chromophores, dyes can be mainly classified as azo, acridine arylmethane, anthraquinone, nitro, xanthenes, quinine-amine, etc. [2]. Azo dyes are the most widely used dye class, with more than $60 \%$ of the total dye production worldwide [3]. These dyes can be fragmented by reductive cleavage of the azo group to generate harmful aromatic amines. Some dyes and aromatic amines have been classified as carcinogenic and genotoxic by the International Agency for Research on Cancer [4]. The presence of toxic and carcinogenic products in textile dyeing effluents is a problem added because of the high colouration inherent in this type of effluents $[5,6]$.

Dyes are also classified according to their application methods. In this respect, the main dye classes are acid, basic, direct, disperse, reactive, sulphur and vat. Among them, the reactive ones are the most widely used in the dyeing of cotton and other cellulosic fibres as they provide high washing fastness and brilliant colours. Reactive dyes represent $25 \%$ of the total dye world market [7]. However, these dyes have a relatively low degree of fixation (70-90\%) [8]. As the unfixed dyes are hydrolysed and cannot be reused, substantial amounts of unfastened dyes are released in the wastewater. In addition, the reactive dye effluents have high salinity due to the significant amount of electrolyte, generally $\mathrm{NaCl}$, added in the dyeing process to increase the dye fixation. About $50-80 \mathrm{~g} \cdot \mathrm{L}^{-1}$ of salt is added during the reactive dyeing [9].

The degradation rate of residual reactive dyes by conventional biological treatment is very poor, as they are recalcitrant and have low biodegradability [10]. As biological treatments are not able to remove colour properly, the application of specific treatments is required in 
order to accomplish current water discharge regulations. There are different techniques to achieve colour removal, among them the most used are: adsorption methods $[11,12]$, membrane filtration $[13,14]$, coagulation and electrocoagulation processes $[15,16]$.

In recent years it has been a growing interest in the use of advanced oxidation methods [1721]. The Fenton process has shown to be effective in the degradation of both soluble and insoluble dyes. However, this method produces an iron sludge and it can only be applied at $\mathrm{pH}$ about $3[22,23]$. The use of AOPs with ultrasound irradiation for the degradation of textile dyes has been also investigated. This combination, especially with Fenton process, has shown an increase in the efficiency of dyes degradation $[23,24]$. On the other hand, electrochemical techniques are able to effectively decolourize dyes. They offer advantages in the treatment of highly coloured textile wastewater including use of the salt already present in the effluents as an electrolyte, absence of any deliberately added organic or inorganic compounds, non-generation of additional wastes and the possible reuse of the treated effluents [25-27]. The UV irradiation during the electrolysis enhances the dye degradation $[7,28]$.

Dye oxidation can occur directly on the electrode surface but it mostly takes place by action of molecules formed at the anode. This process is generally known as indirect oxidation. In this respect, reactive oxygen species such hydroxyl radical $(\bullet \mathrm{OH})$, hydrogen peroxide and ozone can be generated from water by discharge at the anode $[29,30]$.

In addition, in the case of reactive dyebaths, the chloride ions used as dyeing electrolyte play an important role in improving the efficiency of the electrochemical treatment due to the generation of chlorine oxidants $\left(\mathrm{Cl}_{2}, \mathrm{OCl}^{-}\right.$and chlorine radicals) $[31,32]$.

In this work, an electrochemical treatment in a batch cell using Ti/Pt anode was applied to degrade two reactive azo dyes, Colour Index Reactive Orange 4 (RO4) and Colour Index Reactive Orange 13 (RO13), in the presence of chloride ions to simulate the conditions of exhausted reactive dyebaths. The relevance of this study is to optimize the most important factors related with the electrochemical decolouration of the reactive dyes with the aim to 
reduce the treatment time and the electrical consumption of the treatment. Consequently, the kinetics of decolouration for both dyes were studied. The kinetics constants were modelled to evaluate the influence of several factors $(\mathrm{pH}$, conductivity, dye concentration and reactive group structure) characteristic of reactive dye effluents. As some results exhibit two different kinetics curves, this change in the kinetics behaviour was also modelled. Finally, the adjustment of the experimental results to the estimated models was studied.

Our previous studies indicated that decolouration kinetics is much higher than mineralization kinetics since the first one entails the chromophore group breakdown whereas the second one implies the complete degradation of the dye molecule [33]. For this reason, this work was only focused on the decolouration which implies partial dye mineralization.

\section{Materials and Methods}

\subsection{Reagents and dye hydrolysis}

Dyestuffs RO4 and RO13 for the experimental study were supplied by DyStar (Spain). As shown in Figure 1 both dyes have a similar chemical structure except the reactive group of dichlorotriazine in RO4 and monochlorotriazine in RO13.

C.I. Reactive Orange 4 (RO4)<smiles>CN(c1ccc2c(O)c(N=Nc3ccc4c(S(N)(=O)=O)cccc4c3S(C)(=O)=O)c(S(=O)(=O)O)cc2c1)c1nc(Cl)nc(Cl)n1</smiles>

C.I. Reactive Orange 13 (RO13)<smiles>CN(c1ccc2c(O)c(N=Nc3ccc4c(S(N)(=O)=O)cccc4c3[N+](=O)[O-])c([N+](=O)[O-])cc2c1)c1nc(N)nc(Cl)n1</smiles>

Figure 1. Chemical structure of dyes.

For each dye, solutions at different concentrations $\left(0.1,1\right.$ and $\left.2 \mathrm{~g} \cdot \mathrm{L}^{-1}\right)$ were prepared. To simulate industrial wastewater conditions, dyes were hydrolysed before the electrochemical 
treatment. The dye hydrolysis was carried out by boiling the solutions at pH 12 (adjusted with $\mathrm{NaOH}$ ) for $1 \mathrm{~h}$. The solutions were allowed to cool to room temperature and finally, the $\mathrm{pH}$ and conductivity were adjusted with $\mathrm{HCl}$ and $\mathrm{NaCl}$ according to conditions fixed for each experiment (see section 2.2).

\subsection{Experimental design}

For each dye a factorial experimental design of 3 factors and 2 levels $\left(2^{3}\right)$ with one central point was selected to study the influence of the 3 main system factors, namely, $\mathrm{pH}$, conductivity $(\mu)$ and dye concentration (C). The values fixed for these factors are indicated in Table 1.

Table 1. Values of $\mathrm{pH}$, conductivity and dye concentration for each experiment.

\begin{tabular}{cccc}
\hline Exp. num. & pH & $\begin{array}{c}\text { Conductivity }(\mu) \\
\left(\mathbf{m S} \cdot \mathbf{c m}^{-1}\right)\end{array}$ & $\begin{array}{c}\text { dye concentration } \\
(\mathbf{C})\left(\mathbf{g} \cdot \mathbf{L}^{-\mathbf{1}}\right)\end{array}$ \\
\hline II & 5 & 10 & 2 \\
III & 5 & 50 & 2 \\
IV & 9 & 10 & 2 \\
V & 9 & 50 & 0.1 \\
VI & 5 & 10 & 0.1 \\
VII & 9 & 10 & 0.1 \\
VIII & 5 & 50 & 0.1 \\
\hline
\end{tabular}




\subsection{Electrochemical treatment}

The electrochemical treatment was performed in a batch electrochemical cell with $15 \mathrm{~L}$ poly(methylmethacrylate) vessel containing the electrodes located at the bottom. The cathode was constituted by a holed stainless steel plate with the borders rolled forming two hollow cylinders. The anode was constituted by two Ti/Pt bars placed inside the cylinders (anodic surface: $150 \mathrm{~cm}^{2}$ ).

The electrical source voltage was fixed at $7 \mathrm{~V}$ and, consequently, the current intensity $(\mathrm{I})$ was variable $(10 \mathrm{~A} \leq \mathrm{I} \leq 25 \mathrm{~A})$ according to the solution conductivity $\left(10,30\right.$ or $\left.50 \mathrm{mS} \cdot \mathrm{cm}^{-1}\right)$. The current supply was stopped when reaching 95\% decolouration. The maximum treatment time was set to 120 minutes. The decolouration was monitored as a function of the specific applied charge $Q\left(A \cdot h \cdot L^{-1}\right)$ that is a normalized parameter.

\subsection{Kinetics studies}

The electrochemical dye degradation follows a pseudo-first order reaction [25], in which the decolouration rate is related by the expression:

$$
\ln \left(\mathrm{C}_{\mathrm{Q}} / \mathrm{C}_{0}\right)=\mathrm{k} \cdot \mathrm{Q}
$$

where $C_{Q}$ is the dye concentration $\left(g \cdot L^{-1}\right)$ at a specific applied charge $Q\left(A \cdot h \cdot L^{-1}\right)$ and $C_{0}$ the initial dye concentration $\left(g \cdot L^{-1}\right)$ and $k$ is the decolouration kinetic rate $\left(A^{-1} \cdot h^{-1} \cdot L\right)$.

Decolouration was calculated in \% from absorbance measurements carried out with an UV-visible spectrophotometer (Shimadzu UV-2401PC) at $488 \mathrm{~nm}$ for both dyes. This wavelength corresponds to the maximum absorption of the visible spectrum registered for each dye. 


\section{Results and Discussion}

\subsection{Kinetics study of the decolouration process}

Based on Eq. (1), the kinetics decolouration plots obtained for RO4 and RO13 are shown in Figure 2. Kinetics plot (a) and (b) correspond to those obtained using $2 \mathrm{~g} \cdot \mathrm{L}^{-1}$ of dyes (except trial IX where $1 \mathrm{~g} \cdot \mathrm{L}^{-1}$ of dyes was used). Kinetics plot (c) and (d) correspond to those obtained using $0.1 \mathrm{~g} \cdot \mathrm{L}^{-1}$ of dyes. In general kinetics curves exhibit two different slopes (except trials VII and VIII). The first slope is always lower than the second one. Taking into account this behaviour, two different kinetics constants $\left(k_{1}\right.$ and $\left.k_{2}\right)$ were adjusted in most of experiments whereas only one kinetics curve is observed for both dyes in trials VII and VIII (low dye concentration and high conductivity).
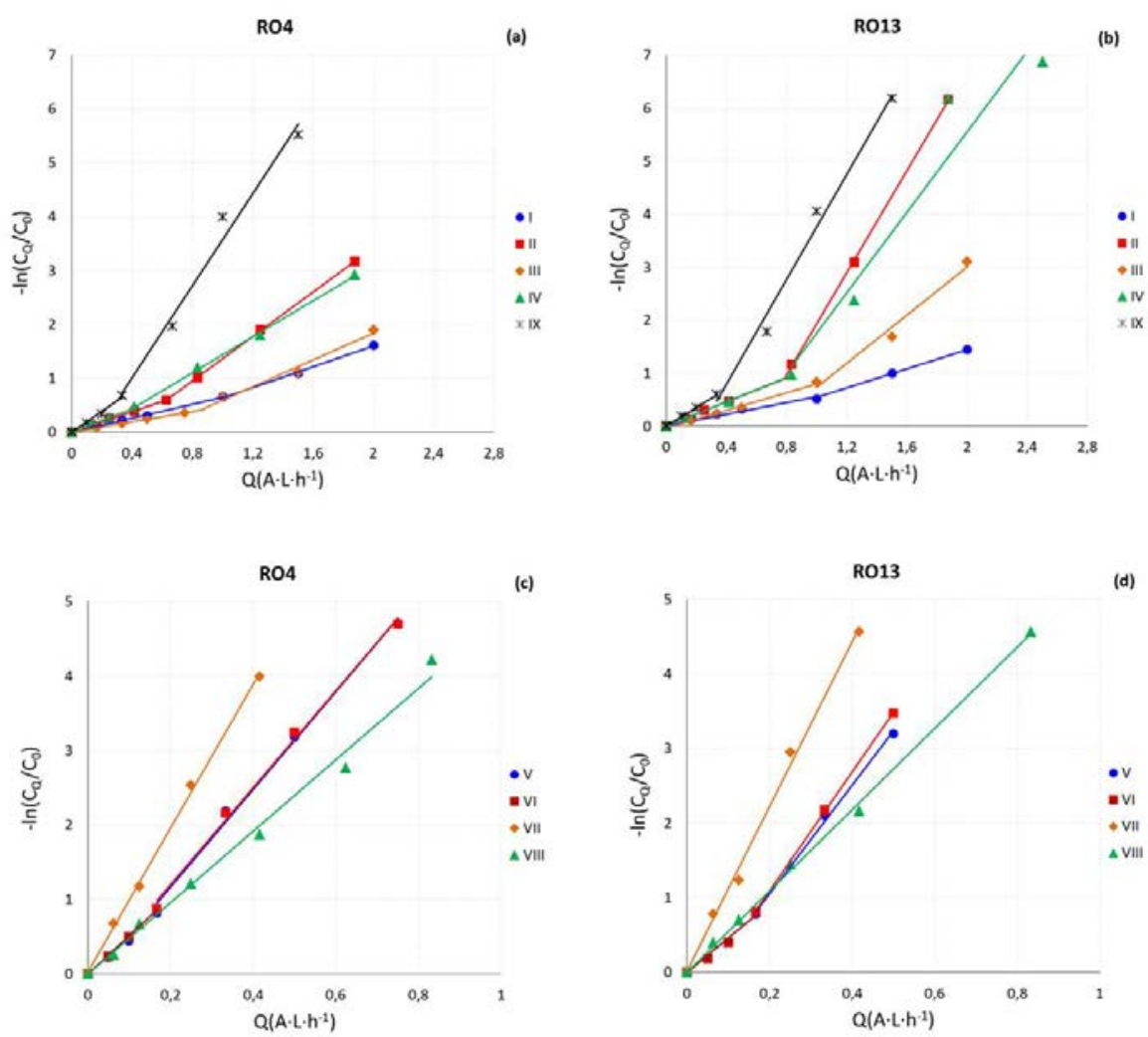

Figure 2. Kinetic decolouration rates for dyes RO4 and RO13. (a) and (b) higher dye concentrations $\left(2 \mathrm{~g} \cdot \mathrm{L}^{-1}\right.$ for all experiments, except $1 \mathrm{~g} \cdot \mathrm{L}^{-1}$ for trial IX); (c) and (d) dye concentration $0.1 \mathrm{~g} \cdot \mathrm{L}^{-1}$. 
In Table 2 are presented the kinetics constants $\left(k_{1}\right.$ and $\left.k_{2}\right)$ calculated from the slopes of the plots in Figure 2. The breaking point $\left(\mathrm{Q}_{B}\right)$, which corresponds to specific applied charge in the intersection of the two kinetics curves, is also presented.

Table 2. Experimental kinetics constants $\left(k_{1}\right.$ and $\left.k_{2}\right)$ and specific applied charge at $\mathrm{Q}_{\mathrm{B}}$.

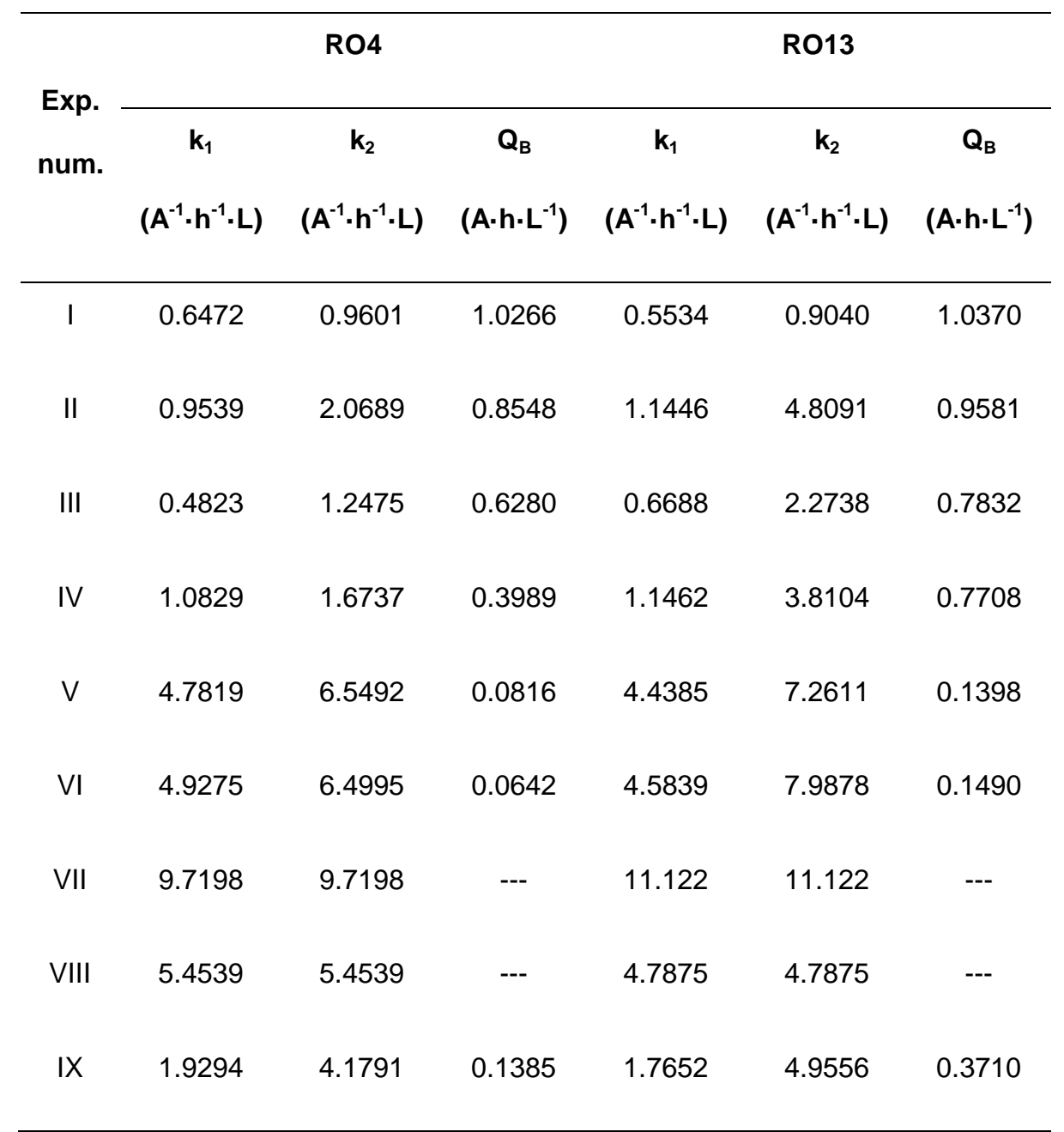

As can be seen from Tables 1 and 2, for a fixed dye concentration, the higher conductivity solutions are decoloured faster than the lower ones. The major content of salts increases the 
electron transfer through the solution. The only exception is $\mathrm{k}_{2}$ of experiments $\mathrm{VI}$ and VIII, where the $\mathrm{pH}$ effect or other factor interactions are probably more significant.

In addition, Figure 2 and Table 2 evidence that the decolouration kinetics is faster for diluted dye solution. For several experiments, two different decolouration kinetics rates were obtained, mainly in the case of the concentrated dye solutions. Up to $50 \%$ decolouration, the reaction occurs more slowly $\left(\mathrm{k}_{1}\right)$ and from this point, the kinetics become faster $\left(\mathrm{k}_{2}\right)$. It can be noted that some diluted dye solutions also showed two kinetics curves (low conductivity trials $\mathrm{V}$ and $\mathrm{VII}$ ), although the two slopes are very similar. However, only one kinetics constant is observed at low dye concentration and high conductivity trials (VII and VIII). Kinetics constants $\mathrm{k}_{1}$ and $\mathrm{k}_{2}$ are modelled in section 3.2.

The different decolouration rates observed along the experiments can be attributed to a change in the mechanism of the dye oxidation. In order to verify whether the amount of oxidant species could cause this change in the mechanism, $\mathrm{Q}_{\mathrm{B}}$ 's are also modeled in Section 3.3.

\subsection{Modeling of decolouration kinetics constants}

Kinetics constants $\mathrm{k}_{1}$ and $\mathrm{k}_{2}$ were modeled with respect to control factors: dye concentration, conductivity and $\mathrm{pH}(\mu, \mathrm{C}$ and $\mathrm{pH})$. It was firstly necessary to elucidate if RO4 and RO13 showed significant differences and should be modeled together or separately.

A combined statistical study, which provided information on whether factors affect equally both dyes, was carried out. With this purpose, a special dummy variable, DV, was defined as follows: the value -1 was assigned to RO4 and +1 to RO13. For the combined dyes study, the $k_{1}$ and $k_{2}$ initial models were set, according to regression analysis, by means of the Eq. (2).

$$
\begin{aligned}
\hat{\mathrm{k}}=\beta_{0}+\beta_{\mathrm{C}} \cdot \mathrm{C} & +\beta_{\mathrm{pH}} \cdot \mathrm{pH}+\beta_{\mu} \cdot \mu+\beta_{\mathrm{C} \cdot \mathrm{pH}} \cdot \mathrm{C} \cdot \mathrm{pH}+\beta_{\mathrm{C} \cdot \mu} \cdot \mathrm{C} \cdot \mu+\beta_{\mathrm{pH} \cdot \mu} \cdot \mathrm{pH} \cdot \mu+\beta_{\mu^{2}} \cdot \mu^{2}+\beta_{\mathrm{DV}} \cdot \mathrm{DV} \\
& +\beta_{\mathrm{pH} \cdot \mathrm{DV}} \cdot \mathrm{pH} \cdot \mathrm{DV}+\beta_{\mu \cdot \mathrm{DV}} \cdot \mu \cdot \mathrm{DV}+\beta_{\mathrm{C} \cdot \mathrm{DV}} \cdot \mathrm{d} \cdot \mathrm{DV}
\end{aligned}
$$


All $\beta$ coefficients were calculated using Microsoft Office Excel 2013. Coefficients with $p$-value $>0.05$ were considered not significant and the corresponding terms were removed step by step. Then the model was recalculated with only the significant terms (stepwise regression). Results are shown in Table 3 and Table 4.

Table 3. Results of Regression for $\hat{\mathrm{k}}_{1}$.

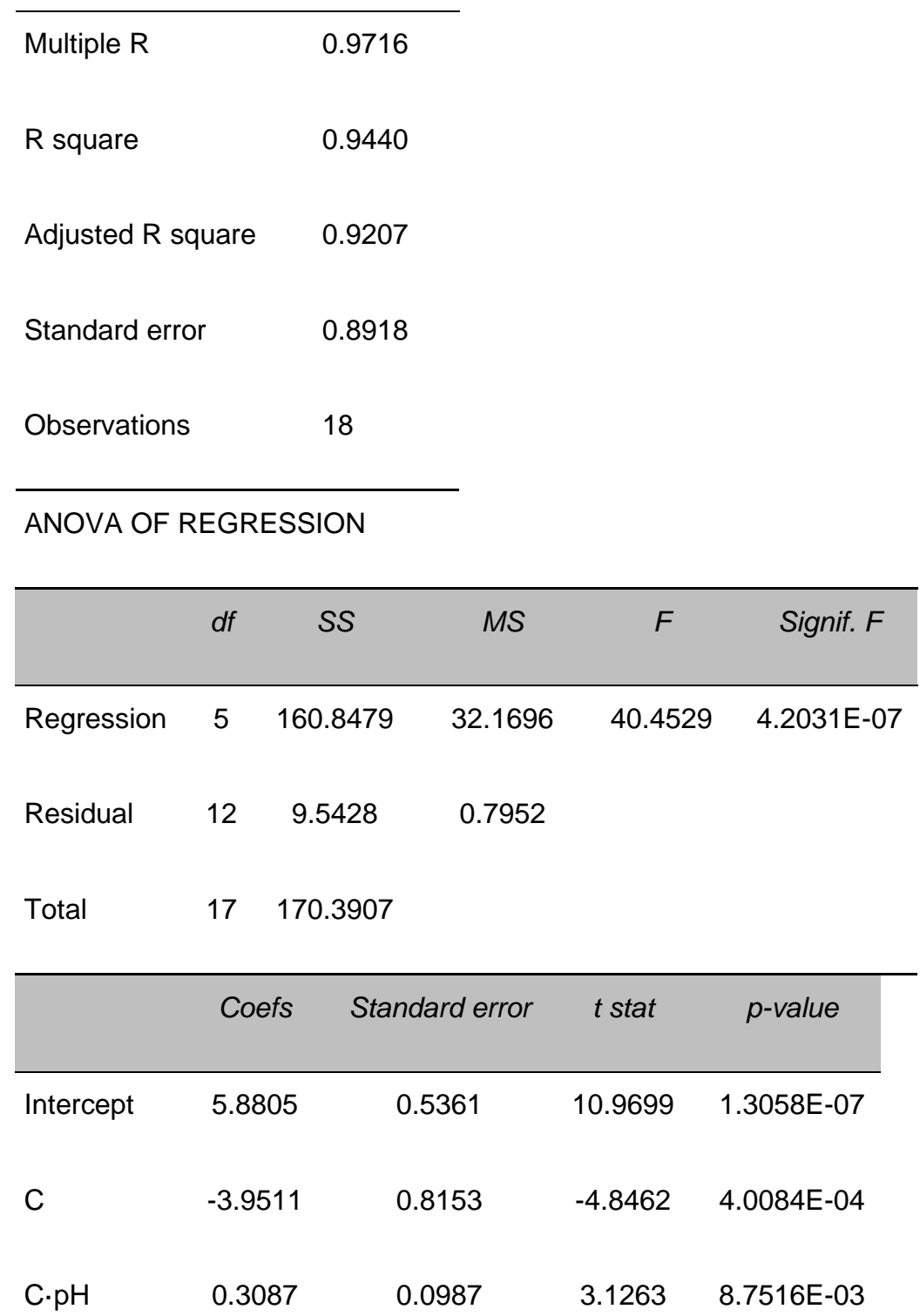




\begin{tabular}{lllll}
$\mathrm{C} \cdot \mu$ & -0.0348 & 0.0117 & -2.9901 & $1.1273 \mathrm{E}-02$ \\
$\mathrm{pH} \cdot \mu$ & -0.0203 & 0.0038 & -5.3559 & $1.7196 \mathrm{E}-04$ \\
$\mu^{2}$ & 0.0037 & 0.0005 & 7.3255 & $9.1531 \mathrm{E}-06$ \\
\hline
\end{tabular}

Table 3 shows that $k_{1}$ is independent on the dye, as the terms containing the dummy variable (DV) are not significant. Therefore, both dyes have the same behaviour at the beginning of the decolouration process. Results of regression analysis infer the $k_{1}$ model $\left(\widehat{\mathrm{k}}_{1}\right)$, as can be seen in Eq. (3).

$$
\hat{\mathrm{k}}_{1}=5.8805-3.9511 \cdot \mathrm{C}+0.3087 \cdot \mathrm{C} \cdot \mathrm{pH}-0.0348 \cdot \mathrm{C} \cdot \mu-0.0203 \cdot \mathrm{pH} \cdot \mu+0.0037 \cdot \mu^{2}(3)
$$

In this model, $\hat{\mathrm{k}}_{1}$ depends on the dye concentration (C), the $\mathrm{pH}$ and the conductivity $(\mu)$. The influence of $\mathrm{d}$ is both as individual factor and as an interaction with $\mathrm{pH}$ and conductivity. In addition, the conductivity also interacts with $\mathrm{pH}$ and presents a clear quadratic effect as individual factor. As the same model for $\hat{\mathrm{k}}_{1}$ is applicable to the two dyes, it can be inferred that the reactive group is not relevant in this reaction step: the differences in their chemical structure do not have any influence in the initial decolouration process, before $\mathrm{Q}_{\mathrm{B}}$.

The influence of factors is shown in Figure 3 which corresponds to the response surfaces of $\widehat{\mathrm{k}}_{1}$ obtained from Eq. (3).
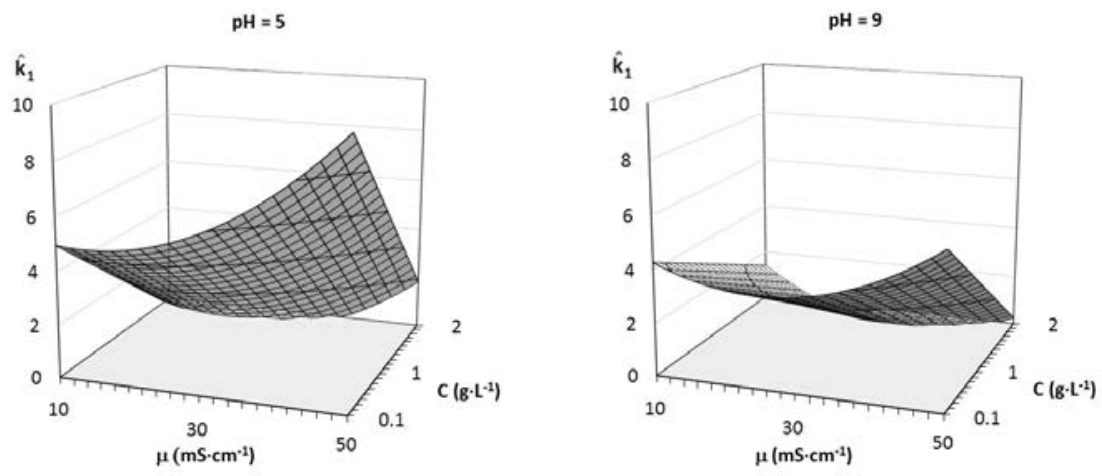
Figure 3. Response surfaces of $\hat{\mathrm{k}}_{1}$ respect to the factors (conductivity and dye concentration) at $\mathrm{pH}=5$ and $\mathrm{pH}=9$.

As expected from the model equation, complex surface responses are obtained and it is difficult to evaluate graphically the influence on each factor. However it can be seen that the kinetics behaviour is very dependent on the $\mathrm{pH}$. At $\mathrm{pH} 5$, higher conductivity and lower dye concentration provide faster decolouration whereas the effect of these factors is less remarkable at $\mathrm{pH} 9$.

The $\hat{\mathrm{k}}_{2}$ model was also obtained from Eq. (2). Results of regression are displayed in Table 4.

Table 4. Results of Regression for $\hat{\mathrm{k}}_{2}$.

\begin{tabular}{|c|c|c|c|c|c|}
\hline \multicolumn{2}{|l|}{ Multiple R } & 0.9496 & & & \\
\hline \multicolumn{2}{|l|}{ R square } & 0.9018 & & & \\
\hline \multicolumn{2}{|c|}{ Adjusted R square } & 0.8715 & & & \\
\hline \multicolumn{2}{|c|}{ Standard error } & 1.0799 & & & \\
\hline \multicolumn{2}{|l|}{ Observations } & 18 & & & \\
\hline \multicolumn{6}{|c|}{ ANOVA OF REGRESSION } \\
\hline & $d f$ & SS & MS & $F$ & Signif. $F$ \\
\hline Regression & 4 & 139.1573 & 34.7893 & 29.8339 & 1.9326E-06 \\
\hline Residual & 13 & 15.1593 & 1.1661 & & \\
\hline
\end{tabular}




\begin{tabular}{|c|c|c|c|c|}
\hline & Coefs & Standard error & $t$ stat & $p$-value \\
\hline Intercept & 6.7354 & 0.5629 & 11.9661 & 2.1619E-08 \\
\hline C & -2.7367 & 0.2841 & -9.6317 & 2.7760E-07 \\
\hline$\mu$ & 0.1331 & 0.0295 & 4.5143 & 5.8190E-04 \\
\hline $\mathrm{pH} \cdot \mu$ & -0.0147 & 0.0037 & -3.9137 & 1.7793E-03 \\
\hline$\mu \cdot D V$ & 0.0178 & 0.0072 & 2.4780 & 2.7713E-02 \\
\hline
\end{tabular}

In contrast with $\hat{\mathrm{k}}_{1}$, the dummy variable DV is present in the $\hat{\mathrm{k}}_{2}$ equation (Eq. (4))

$$
\widehat{\mathrm{k}}_{2}=6.7354-2.7367 \cdot \mathrm{C}+0.1331 \cdot \mu-0.0147 \cdot \mathrm{pH} \cdot \mu+0.0178 \cdot \mu \cdot \mathrm{DV}
$$

The term $\mu \cdot \mathrm{DV}$ in Eq. (4) indicates that the influence of conductivity is different for both dyes. As a result, the following equations (Eq. (5) and (6)) are obtained:

$$
\begin{aligned}
& \text { RO4: } \hat{\mathrm{k}}_{2}=6.7354-2.7367 \cdot \mathrm{C}+0.1153 \cdot \mu-0.0147 \cdot \mathrm{pH} \cdot \mu \\
& \text { RO13: } \hat{\mathrm{k}}_{2}=6.7354-2.7367 \cdot \mathrm{C}+0.1509 \cdot \mu-0.0147 \cdot \mathrm{pH} \cdot \mu
\end{aligned}
$$

As can be seen, $\hat{\mathrm{k}}_{2}$ expressions are simpler than $\hat{\mathrm{k}}_{1}$. Both $\hat{\mathrm{k}}_{2}$, only show influence of dye concentration and conductivity as individual terms. The interaction of $\mathrm{pH}$ and $\mu$ was also found.

Moreover, it can be noted that both $\hat{\mathrm{k}}_{2}$ are very similar. There is only a slight difference in the individual conductivity term $(\mu)$ whereas the rest of coefficients are identical. Surface responses at $\mathrm{pH} 5$ and pH 9, obtained from Eq. (5) and Eq. (6), are plotted in Figure 4. 

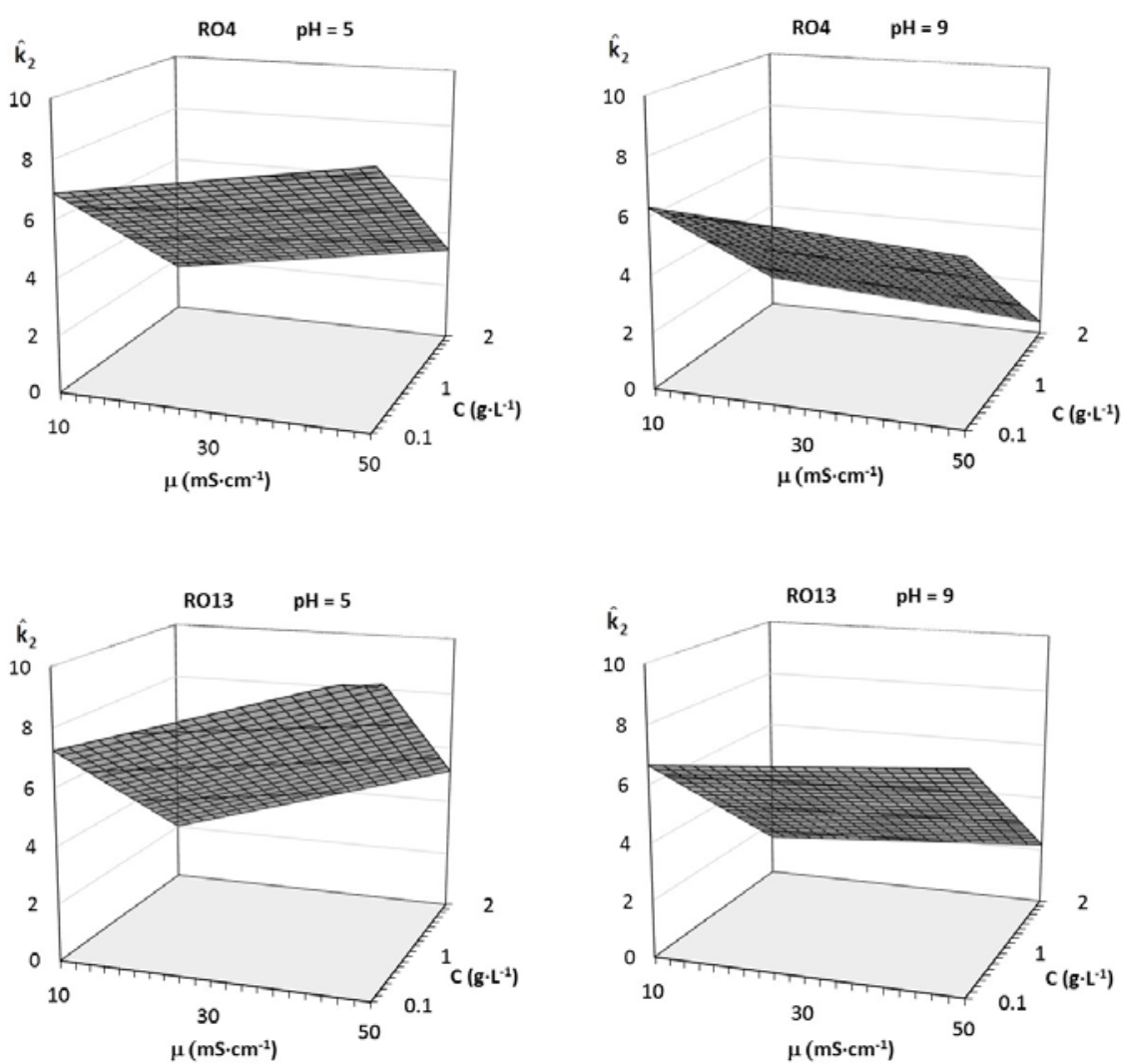

Figure 4. Response surfaces of $\hat{\mathrm{k}}_{2}$ with respect to the conductivity and dye concentration for dyes $\mathrm{RO} 4$ and $\mathrm{RO} 13$ at $\mathrm{pH}=5$ and $\mathrm{pH}=9$.

It can be seen that, for both dyes, the effect of conductivity on $\hat{\mathrm{k}}_{2}$ is rather small at $\mathrm{pH} 9$ whereas a marked increase of $\mu$ influence is observed at $\mathrm{pH} 5$.

To evaluate the adjustment of the obtained models, the experimental kinetics constants ( $k_{1}$ and $\mathrm{k}_{2}$ ) were compared in Figure 5 with the ones calculated from models $\left(\hat{\mathrm{k}}_{1}\right.$ and $\left.\hat{\mathrm{k}}_{2}\right)$. 

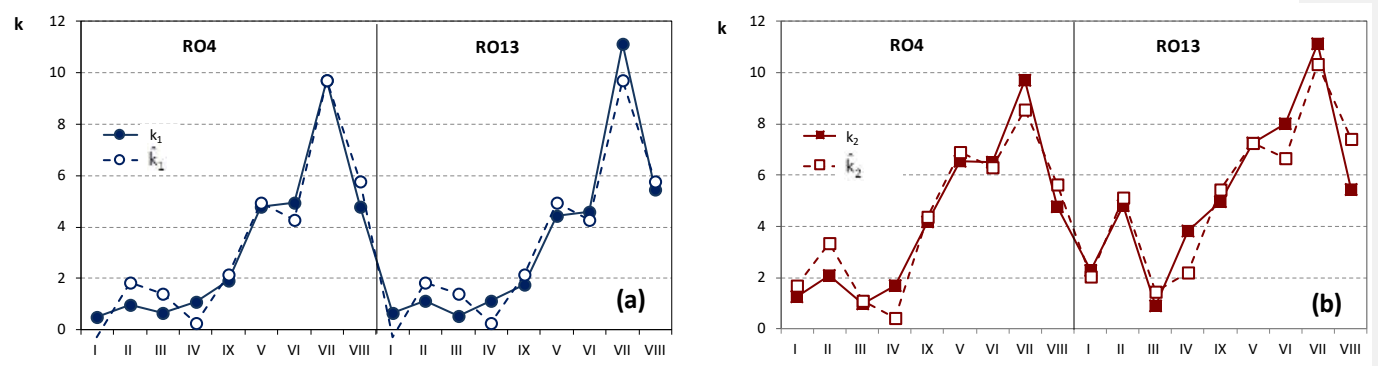

Figure 5. Comparison of experimental kinetic constants and modeled constants (a)

$\mathrm{k}_{1}$ and $\hat{\mathrm{k}}_{1}$ (b) $\mathrm{k}_{2}$ and $\hat{\mathrm{k}}_{2}$.

As can be seen in Figure 5 a good correlation between the modeled and the experimental constants was generally observed. In some particular points (such as I and IV) there is a lower correlation degree for $k_{1}$. These points correspond to the slowest kinetics, which can probably occur through a different mechanism of reaction.

\subsection{Modeling of specific applied charge at the breaking point $Q_{B}$}

As indicated, the breaking point $\left(\mathrm{Q}_{\mathrm{B}}\right)$ corresponds to specific applied charge in the intersection of the two kinetics curves. On the basis of the initial model indicated in section 3.2 (Eq. (2)), the $\mathrm{Q}_{B}$ values were modelled. Results of stepwise regression for $\widehat{Q}_{B}$ are indicated in Table 5.

Table 5. Results of Regression for $\widehat{Q}_{B}$

Multiple R

R square

Adjusted R square
0.9923

0.9846

0.9750 


\begin{tabular}{|c|c|c|c|c|c|}
\hline \multicolumn{6}{|c|}{ ANOVA OF REGRESSION } \\
\hline & $d f$ & SS & MS & $F$ & Signif. F \\
\hline Regression & 5 & 1.8069 & 0.3614 & 102.2108 & 4.9980E-07 \\
\hline Residual & 8 & 0.0283 & 0.0035 & & \\
\hline \multirow[t]{2}{*}{ Total } & 13 & 1.8352 & & & \\
\hline & Coefs & \multicolumn{2}{|c|}{ Standard error } & t stat & $p$-value \\
\hline Intercept & -0.0517 & \multicolumn{2}{|c|}{ 8.1708E-02 } & -0.6327 & 5.4460E-01 \\
\hline $\mathrm{C} \cdot \mathrm{pH}$ & -0.0404 & \multicolumn{2}{|c|}{ 5.2524E-03 } & -7.7009 & 5.7389E-05 \\
\hline$\mu$ & 0.0424 & \multicolumn{2}{|c|}{ 8.4668E-03 } & 5.0058 & 1.0453E-03 \\
\hline$C \cdot \mu$ & 0.0683 & \multicolumn{2}{|c|}{ 4.2912E-03 } & 15.9196 & 2.4275E-07 \\
\hline$\mu^{2}$ & -0.0030 & \multicolumn{2}{|c|}{ 2.5774E-04 } & -11.7748 & 2.4765E-06 \\
\hline$\mu \cdot D V$ & 0.0027 & \multicolumn{2}{|c|}{ 5.2972E-04 } & 5.0664 & 9.6928E-04 \\
\hline
\end{tabular}

The presence of the term $\mu \cdot \mathrm{DV}$ in Table 5 evidences a different effect of the conductivity on $\mathrm{Q}_{B}$ for each dye. This implies that, as in the case of $\mathrm{k}_{2}$, the $\widehat{\mathrm{Q}}_{\mathrm{B}}$ must be different for RO4 and RO13 (Eq. (7) and (8)).

$$
\begin{aligned}
& \text { RO4: } \quad \widehat{Q}_{B}=-0.0517-0.0404 \cdot C \cdot p H+0.0397 \cdot \mu+0.0683 \cdot C \cdot \mu-0.0030 \cdot \mu^{2} \\
& \text { R013: } \quad \widehat{Q}_{B}=-0.0517-0.0404 \cdot C \cdot p H+0.0451 \cdot \mu+0.0683 \cdot C \cdot \mu-0.0030 \cdot \mu^{2}
\end{aligned}
$$


From Eq. (7) and (8) it can be stated that $\widehat{Q}_{B}$ decreases when $\mathrm{pH}$ increases due to the effect of the interaction of dye concentration and $\mathrm{pH}$, term $\mathrm{C} \cdot \mathrm{pH}$ with negative coefficient. This effect is more significant for high dye concentration.

In addition, $\widehat{Q}_{B}$ is highly influenced by the conductivity through a positive linear term, a negative quadratic term and a positive interaction with the dye concentration. It should be noted that the conductivity in this work is related to the $\mathrm{NaCl}$ concentration. The major dependence of $\mathrm{Q}_{\mathrm{B}}$ on dye concentration and conductivity could be an expected result, as the dye electro-oxidation occurs through an indirect reaction with the oxidant species generated from the oxidation of chloride ions. Also the influence of $\mathrm{pH}$ is predictable due to its effect on equilibrium of the generated oxidant species.

Finally, the Figure 6 shows that a good correlation between $\widehat{Q}_{B}$ and the experimental $Q_{B}$ is generally observed.

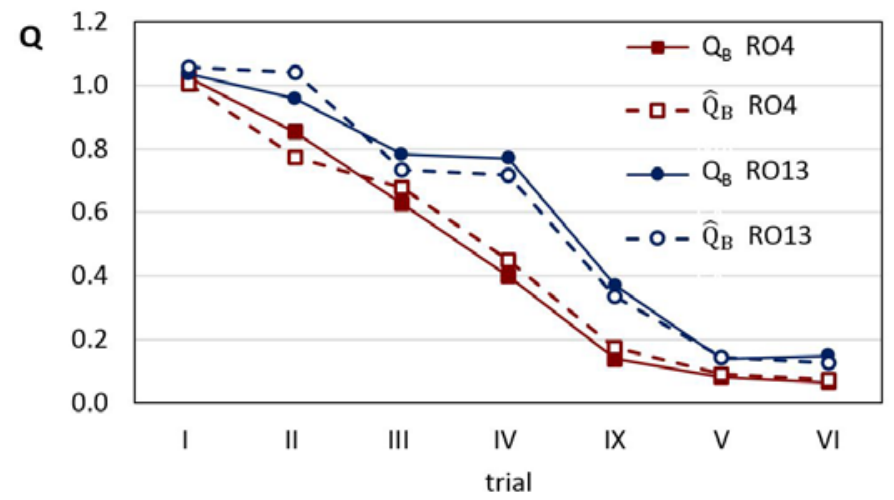

Figure 6. Comparison between modeled and experimental $\mathrm{Q}_{\mathrm{B}}$ values.

The relevance of $Q_{B}$ in the progress of the decolouration evidences that there are different mechanisms of the decolouration reactions and that several factors are crucial in the progress of this type of reactions. 


\section{Conclusions}

The decolouration kinetics curves of both reactive dyes, RO4 and RO13, based on pseudo-first order reactions were studied, according to specified conditions, using a $2^{3}$ experimental design with one central point. The experiments at low dye concentration and high conductivity exhibited only one kinetics constant, $\mathrm{k}_{1}$, whereas the rest of experiments showed two different kinetics curves. In this case a breaking point was observed. This behaviour was attributed to a change in the decolouration mechanism.

The kinetics constants $k_{1}$ and $k_{2}$ were modeled and the corresponding surface responses were plotted. A unique model of $k_{1}$ was obtained for both dyes, whereas $k_{2}$ presented different models for RO4 and RO13 that show slight differences in the conductivity coefficient.

In the electrochemical decolouration of both dyes, the most influent factor in $k_{1}$ and $k_{2}$ models is the dye concentration. The other studied factors (conductivity and $\mathrm{pH}$ ) are also significant, either individually or through different interactions.

Finally, the specific applied charges at the breaking point, $\mathrm{Q}_{\mathrm{B}}$, were also modeled. As expected, conductivity was found to be the main factor in the model equation as this parameter plays an important role in the generation of oxidant species during the electrochemical treatment.

Acknowledgments: The authors would like to thank the Spanish Ministry of Economy and Competitiveness for its financial support (Project CTM2012-31461). 


\section{References}

[1] P.N. Patel, H.S. Patel, Removal and decolorization of dye bearing textile effluents by sulfinated furfural-acetone resin, Pelagia Res. Libr. Adv. Appl. Sci. Res., 3 (2012) 26932699.

[2] M.A. Rauf, S. Salman Ashraf, Survey of recent trends in biochemically assisted degradation of dyes, Chem. Eng. J., 209 (2012) 520-530.

[3] M. Solís, A. Solís, H.I. Pérez, N. Manjarrez, M. Flores, Microbial decolouration of azo dyes: A review, Process Biochem., 47 (2012) 1723-1748.

[4] IARC, Overall Evaluation of Carcinogenicity to Humans, Lyon-France, 2004.

[5] V. López-Grimau, M. Riera-Torres, M. López-Mesas, C. Gutiérrez-Bouzán, Removal of aromatic amines and decolourisation of azo dye baths by electrochemical treatment, Color. Technol., 129 (2013) 267-273.

[6] C. Zaharia, A. Muresan, A. Popescu, D. Suteu, R. Muresan, Using of Industrial Waste Materials for Textile Wastewater Treatment, Environ. Eng. Manag. J., 8 (2009) 1097-1102. [7] M. Sala, V.V. López-Grimau, C. Gutiérrez-Bouzán, Photo-Electrochemical Treatment of Reactive Dyes in Wastewater and Reuse of the Effluent: Method Optimization, Materials, 7 (2014) 7349-7365.

[8] M. Pepió, M.C. Gutiérrez-Bouzán, Empirical Models for the Decoloration of Dyes in an Electrochemical Batch Cell, Ind. Eng. Chem. Res., 50 (2011) 8965-8972.

[9] V. López-Grimau, C. Gutiérrez-Bouzán, Selection of Decolorization Methods of Reactive Dye Baths for Reuse Purposes, in: J. Fu (Ed.), Dye. Process. Tech. Appl., New York 2013, pp. 205-215.

[10] T.H. Kim, C. Park, S. Kim, Water recycling from desalination and purification process of reactive dye manufacturing industry by combined membrane filtration, J. Clean. Prod., 13 (2005) 779-786. 
[11] E. García, R. Medina, M. Lozano, I. Hernández Pérez, M. Valero, A. Franco, Adsorption of Azo-Dye Orange II from Aqueous Solutions Using a Metal-Organic Framework Material: Iron- Benzenetricarboxylate, Materials, 7 (2014) 8037-8057.

[12] G. Kyzas, G. Z., A Decolorization Technique with Spent "Greek Coffee" Grounds as Zero-Cost Adsorbents for Industrial Textile Wastewaters, Materials, 5 (2012) 2069-2087.

[13] A. Aouni, C. Fersi, B. Cuartas-Uribe, A. Bes-Pía, M.I. Alcaina-Miranda, M. Dhahbi, Reactive dyes rejection and textile effluent treatment study using ultrafiltration and nanofiltration processes, Desalination, 297 (2012) 87-96.

[14] V. Buscio, M. Crespi, C. Gutiérrez-Bouzán, Application of PVDF ultrafiltration membranes to treat and reuse textile wastewater, Desalin. Water Treat., 57 (2016) 8090_ 8096.

[15] B.K. Nandi, S. Patel, Effects of operational parameters on the removal of brilliant green dye from aqueous solutions by electrocoagulation, Arab. J. Chem., 10 (2017) 2961-2968.

[16] M. Vilaseca, V. López-Grimau, C. Gutiérrez-Bouzán, Valorization of Waste Obtained from Oil Extraction in Moringa Oleifera Seeds: Coagulation of Reactive Dyes in Textile Effluents, Materials, 7 (2014) 6569-6584.

[17] J. Chung, J.-O. Kim, Application of advanced oxidation processes to remove refractory compounds from dye wastewater, Desalin. Water Treat., 25 (2011) 233-240.

[18] A. Zuorro, R. Lavecchia, Evaluation of UV/H2O2 advanced oxidation process (AOP) for the degradation of diazo dye Reactive Green 19 in aqueous solution, Desalin. Water Treat., 52 (2014) 1571-1577.

[19] S. Papić, D. Vujević, N. Koprivanac, D. Šinko, Decolourization and mineralization of commercial reactive dyes by using homogeneous and heterogeneous Fenton and UV/Fenton processes, J. Hazard. Mater., 164 (2009) 1137-1145.

[20] T. Visa, M. Sánchez, V.V. López-Grimau, R. Navarro, S. Reche, M.C. Gutiérrez-Bouzán, C. Gutiérrez-Bouzán, Photocatalysis with titanium dioxide to remove 
colour of exhausted reactive dyebaths without $\mathrm{pH}$ modification, Desalin. Water Treat., 45 (2012) 91-99.

[21] L. Yue, K. Wang, J. Guo, J. Yang, X. Luo, J. Lian, L. Wang, Enhanced electrochemical oxidation of dye wastewater with Fe2O3 supported catalyst, J. Ind. Eng. Chem., 20 (2014) $725-731$.

[22] C.R. Holkar, A.J. Jadhav, D. V. Pinjari, N.M. Mahamuni, A.B. Pandit, A critical review on textile wastewater treatments: Possible approaches, J. Environ. Manage., 182 (2016) 351366.

[23] G. Harichandran, S. Prasad, SonoFenton degradation of an azo dye, Direct Red, Ultrason. Sonochem., 29 (2016) 178-185.

[24] S.G. Cetinkaya, M.H. Morcali, S. Akarsu, C.A. Ziba, M. Dolaz, Comparison of classic Fenton with ultrasound Fenton processes on industrial textile wastewater, Sustain. Environ. Res., 28 (2018) 165-170.

[25] V. López-Grimau, C. Gutiérrez-Bouzán, J. Valldeperas, M. Crespi, Continuous reuse of water and electrolyte from decolorized reactive dyebaths, Desalin. Water Treat., 51 (2013) 4593-4602.

[26] V. López-Grimau, M. del C. Gutiérrez-Bouzán, J. Valldeperas, M. Crespi, Reuse of the water and salt of reactive dyeing effluent after electrochemical decolorisation, Color. Technol., 128 (2012) 36-43.

[27] C. Gutiérrez-Bouzán, M. Pepió, Interaction between pH and Conductivity in the Indirect Electro-oxidation of Azo Dyes, Ind. Eng. Chem. Res., 53 (2014) 18993-19000.

[28] S. Cotillas, D. Clematis, P. Cañizares, M.P. Carpanese, M.A. Rodrigo, M. Panizza, Degradation of dye Procion Red MX-5B by electrolytic and electro-irradiated technologies using diamond electrodes, Chemosphere, 199 (2018) 445-452.

[29] C.A. Martínez-Huitle, E. Brillas, Electrochemical Alternatives for Drinking Water Disinfection, Angew. Chemie Int. Ed., 47 (2008) 1998-2005. 
[30] C. Ramírez, A. Saldaña, B. Hernández, R. Acero, R. Guerra, S. Garcia-Segura, E. Brillas, J.M. Peralta-Hernández, Electrochemical oxidation of methyl orange azo dye at pilot flow plant using BDD technology, J. Ind. Eng. Chem., 19 (2013) 571-579.

[31] A.I. del Río, J. Molina, J. Bonastre, F. Cases, Influence of electrochemical reduction and oxidation processes on the decolourisation and degradation of C.I. Reactive Orange 4 solutions, Chemosphere, 75 (2009) 1329-1337.

[32] E. Petrucci, L. Di Palma, R. Lavecchia, A. Zuorro, Treatment of diazo dye Reactive Green 19 by anodic oxidation on a boron-doped diamond electrode, J. Ind. Eng. Chem., 26 (2015) 116-121.

[33] M. Sala, V. López-Grimau, C. Gutiérrez-Bouzán, Photoassisted Electrochemical Treatment of Azo and Phtalocyanine Reactive Dyes in the Presence of Surfactants, Materials, 9 (2016) 211. 